\title{
Forage Improvement via Marker-Assisted Selection
}

\author{
Brent Barrett $^{1,5}$, Marty Faville ${ }^{1}$, Alieu Sartie ${ }^{1}$, David Hume ${ }^{1}$, Zulfi Jahufer ${ }^{1}$, Michael \\ Hickey $^{1}$, Ivan Baird ${ }^{2}$, Chris Pennell ${ }^{2}$, Doug Ryan ${ }^{3}$, Bruce Cooper ${ }^{4}$, Derek Woodfield ${ }^{1}$, \\ Syd Easton ${ }^{1}$ \\ ${ }^{1}$ AgResearch Grasslands Research Centre, PB 11008, Palmerston North, New Zealand \\ ${ }^{2}$ AgResearch Canterbury Agriculture and Science Centre, PO Box 60, Lincoln, New \\ Zealand \\ ${ }^{3}$ AgResearch Ruakura Research Centre, PB 3123, Hamilton, New Zealand \\ ${ }^{4}$ AgResearch Kerikeri Station, PO Box 23, Kerikeri, Northland, New Zealand \\ ${ }^{5}$ Corresponding Author. email: brent.barrett@agresearch.co.nz
}

Abstract. The use of DNA markers to accelerate genetic improvement of forages presents a unique set of opportunities, challenges, and benefits. Our experiments in full-sib mapping populations of white clover and perennial ryegrass have detected $>75$ quantitative trait loci (QTLs), each with multiple marker:trait associations at specific locations in either the perennial ryegrass or white clover genome. A subset of these QTL are robust (detected in multiple years / sites / populations) and exert a substantial influence on performance, warranting exploration of development for application in Marker-assisted Selection (MAS) breeding programmes. Ryegrass QTLs associated with herbage yield, seed yield, plant size and habit, cold tolerance, seasonal regrowth, and disease have been identified, whereas QTL discovery in white clover has been focused on reproductive traits. Markers from two white clover QTLs were used to develop marker assays suitable for selection of parental plants with superior breeding value for seed yield potential. Tandem testing of the two assays over two field seasons and eight populations indicates that substantial change in seed yield may be achieved (up to 90\% increase), and that the marker / allele / phase relationships to plant performance are population specific. These data point to an opportunity to develop selection tools on a population specific basis, and to a challenge to implement MAS approaches tailored for open-pollinated population breeding systems.

\section{Introduction}

Grazed forage fuels the New Zealand pastoral industry, capturing sunlight to provide energy which animals convert to milk, meat and fibre. Forage improvement programmes in temperate climates are focused on a diverse suite of traits including quality, energy, intake, persistency, disease and pest resistance, stress tolerance, dry matter production, nutrient interception, symbiont interactions, and seed production (Abberton and Marshall 2005, Humphreys et al. 2006). Many of these traits are common among grass and legume forage species, with the added complexity that breeding programmes must deliver superior varieties exhibiting competitive compatibility with an array of other modern forages to consistently deliver high performance diets in mixed swards.

Traditional approaches to plant improvement have delivered steadily improved performance of perennial ryegrass (Lolium perenne L.) and white clover (Trifolium repens L.), the primary grazed forages used in Australasia (Woodfield and Caradus 1994, Woodfield and Easton 2004). However, genetic advances in forage performance are hindered by several bottlenecks in the traditional breeding schemes, including the 
lag phase associated with assessing persistence and performance of perennial plants throughout their life cycle, genetic complexity of some traits, difficulty and expense of acquiring some phenotypic data, complex genetic testing required to fix superior dominant alleles, and challenges in overcoming negative correlations among key components of mega-traits such as herbage yield. Genetic testing, using DNA markers as diagnostic tools to predict performance, may overcome some of these bottlenecks and accelerate the gains from selection achieved in forage improvement programmes.

Genetic tests are being developed to identify individuals with preferred gene profiles, a biotechnology application called Marker-Assisted Selection (MAS). Most MAS effort has focused on the transfer of alleles via back-cross breeding with some success for both qualitative and quantitative effects (Francia et al. 2005). These efforts are primarily focused on plant species with self-compatible mating systems, with approaches to MAS that are markedly different than those appropriate for selfincompatible plant species. However, forages are well positioned to develop approaches for open-pollinated, population-based breeding systems (Kolliker et al. 2005).

The enabling capabilities for development of MAS of quantitative traits include efficient and informative DNA markers, comprehensive genome maps, and structured plant families. These tools are now available in perennial ryegrass (Faville et al. 2004, Warnke et al. 2004) and in white clover (Barrett et al. 2004, Jones et al. 2003).

These resources can be applied to families exhibiting quantitative variation for traits of interest, used to identify regions of the genome (each of which is called a quantitative trait locus or QTL) which influence variation for the traits of interest, and characterise the relative influence of the various QTLs on the trait. This strategy has led to discovery of QTLs in most economic plants, including QTLs influencing seed production in white clover (Barrett et al. 2005), and a range of traits in perennial ryegrass (Faville et al. 2006).

These QTL discoveries provide a number of marker:trait associations which may be tested in breeding populations to create and validate genetic tests for use in a variety of MAS approaches. Markers from QTLs also are a starting point for comparative mapping linking to sequenced model genomes and identifying candidate genes for key traits, which may subsequently be associated with changes in plant performance.

This paper focuses on recent QTL discovery projects in the perennial ryegrass and white clover genomes, on-going work to validate marker:trait associations in independent populations, and development of QTL-associated marker tests for MAS applications.

\section{Methods}

Marker Data

Public and proprietary microsatellite (SSR) markers, sourced from both total genomic and expressed DNA sequence data, were used for the plant genotyping described in this paper. As described by Faville et al. (2003), SSRs were amplified using a three-primer PCR system, amplification products were multiplexed post-PCR, and resolved in an optimised and automated capillary electrophoresis instrument. 
Plant Material and Phenotypic Data

Full-sib $\mathrm{F}_{1}$ families, resulting from pair crosses between highly heterozygous parental genotypes, were used to discover QTL. All trait data were collected on clonal copies of $\mathrm{F}_{1}$ and parental plants. White clover seed yield QTL validation was done in breeding populations, and used the field data collected using standard practice for white clover breeding programmes as described in (Woodfield et al. 2004).

Perennial Ryegrass

Perennial ryegrass is a diploid $(2 n=2 x=14)$ allogamous perennial forage grass. QTL discovery was undertaken in perennial ryegrass populations 'RM2' and 'RM3' ( $n=188$, for each population). RM2 has been explored for a range of traits, including herbage yield and its components, forage quality factors, seed yield and its components, and root distribution. The latter two datasets are discussed elsewhere in this proceedings (Faville et al. 2006, Sartie et al. 2006). Data for herbage yield, plant size and habit, seasonal regrowth and disease were collected from the RM2 population over two seasons (2003/04 and 04/05) encompassing summer, autumn, winter and spring growth periods, from replicated $(n=4)$ spaced plant field trials in Kerikeri, Hamilton and Lincoln NZ. For herbage yield, plant growth scores (PGS) calibrated against dry matter measurements were recorded, with a total of 21 sampling date x site measurements taken. Most measurements $(\mathrm{n}=10)$ were taken during the autumn growth period (March to May).

Population RM3 was assayed for component traits of winter survival. Freezing tolerance data were collected from a controlled environment trial conducted using the New Zealand Controlled Environment Laboratory at Palmerston North. Following 14 days of acclimation at $2^{\circ} \mathrm{C}$, genotype replicates $(n=4)$ in small pots were subjected to freezing treatments (six hours duration) of $-2^{\circ} \mathrm{C},-5^{\circ} \mathrm{C},-8^{\circ} \mathrm{C},-11^{\circ} \mathrm{C}$ or $-14^{\circ} \mathrm{C}$. Shoot material was cut back to $2.0 \mathrm{~cm}$ above soil level 24 hours after treatment. Regrowth (RG) was measured as maximum leaf length six days post-cutting, and a visual score of leaf damage (VSD, 0-9 scale, with $0=$ dead with no growth and $9=$ undamaged) was made 14 days after cutting.

White Clover

White clover is an allotetraploid $(2 n=4 x=32)$ allogamous perennial forage legume. The full-sib population $3647 \times 6525(n=180)$ was used in a QTL discovery programme targeting Seed Yield (SY), and two seed yield components: yield per inflorescence (YI, g/inflorescence), and inflorescence density (ID, number of inflorescences/unit area). The QTL discovery process and outcomes are described in (Barrett et al. 2005).

Two of the major component QTL, 'ID-C2' and 'YI-D2', were both found to influence SY and were subsequently used in genetic test development. ID-C2 is implicated in control of up to $23 \%$ of the variation of ID and SY in population $3647 \times 6525$, and $Y I-D 2$ of up to $29 \%$ of the variation of YI and SY in that same population.

SSR markers associated with these two QTL (up to 8 per QTL) were used to genotype complex, multi-parent breeding populations undergoing pre-commercial field evaluations for SY performance during the 03/04 and 04/05 growing season. Each breeding population consisted of $>180$ plants grown in an unreplicated spaced plant nursery located in Lincoln, NZ and managed under standard breeding programme practices. DNA samples were collected and purified using the FTA paper-based DNA sampling system (www.whatman.com) prior to DNA marker testing (McCallum et al. 2006). 
Statistical Analysis

Perennial ryegrass and white clover trait data were analysed for genotype, site, year, replicate, and interaction effects prior to QTL discovery, using ANOVA algorithms in GenStat 7.0. Genome mapping and subsequent QTL discovery were undertaken using JoinMap 3.0 and MapQTL 4.0, respectively (www.kyazma.nl). Tests for associations between genotype and phenotype in white clover breeding populations were undertaken using t-tests implemented in GenStat, for which significance was declared at $\mathrm{p}<0.01$.

\section{Results \& Discussion}

Ryegrass QTL Discovery

The analysis of variance indicated significant genotype effects for all trial data in RM2 and RM3. In a result that is typical for complex traits, analysis of herbage yield data from the multi-site trial revealed numerous QTLs of predominantly moderate effect (each accounting for $<10 \%$ of trait variation). From 21 sampling date $\mathrm{x}$ site measurements, a total of 54 QTL for PGS were identified, occupying 18 general genome positions across all seven linkage groups. All but two of the identified positions were occupied by 2-5 co-localised QTL.

Subsets of QTLs exhibiting substantial effects on phenotype, consistency among trial environments, and consistency among seasons were identified from among the 54 QTL. A number of these robust QTLs occupy common genome positions that are coincident with QTLs for vegetative growth characteristics measured in a glasshouse trial, notably leaf elongation rate and leaf appearance rate. Markers at these genome positions are prioritised for further validation and for development of genetic tests for MAS programmes targeting improved herbage yield potential.

For freezing tolerance, regrowth (RG) within the RM3 mapping population declined progressively from the $-5^{\circ} \mathrm{C}$ treatment onwards, whilst visual damage (VDS) became apparent from the $-8^{\circ} \mathrm{C}$ treatment onwards. Variation in RG and VDS was greatest within the $-14^{\circ} \mathrm{C}$ treatment, and these values were used for QTL analysis. RG. 14 and VDS ${ }_{-14}$ genotype mean values were correlated $(r=0.7)$ and this was apparent in QTL analysis, which revealed two coincident QTL for both measures, on linkage groups LG5 (qVDS-5 and qRG-5) and LG7 (qVDS-7 and qRG-7). Comparative mapping among perennial ryegrass, rice, and wheat has been used to identify potential candidate genes underlying qVDS-5 in particular. The information from the rice model genome is being used to develop second generation marker assays targeting candidate genes, with the potential to develop markers with a more precise selection capability.

QTL discovery in perennial ryegrass seed yield and root distribution are reported elsewhere in this proceedings (Faville et al. 2006, Sartie et al. 2006).

Clover QTLs and Validation

The results of Barrett et al. (2005) are typical of many QTL discovery efforts. Many QTLs exhibiting small and/or transient effects are identified, while few QTL consistently exhibited major ( $>20 \%$ ) influence on plant performance across years. No QTL had a significant influence on seed yield in all three field seasons. However, two QTLs (ID-C2 and YI-D2) for the respective component traits (ID or YI) were detected in the two seasons that component trait data were collected, and each influenced seed yield in one of the two seasons.

QTL validation experiments using markers associated with ID-C2 and YI-D2 in a breeding population C23759 during the 2003/04 growing season identified two alleles at loci significantly $(\mathrm{p}<0.001)$ associated with SY in that population, including one 
associated with ID-C2 and one associated with YI-D2. Plants in the population containing favourable alleles at both loci exhibited a 90\% increase in seed yield potential relative to those plants which had both of the unfavourable alleles (Figure 1).

A crossing programme is underway to establish populations to assess the breeding value of those individuals which exhibit either one or both favourable marker alleles, relative to those individuals that exhibit either one or both unfavourable marker alleles.

Evaluation of these same markers in 2004/05 across seven white clover breeding populations gave rise to mixed results. The YI-D2 marker test performed well in 2004/05 in terms of data quality, with consistent amplification in all seven populations. Five of the seven populations exhibited a significant $(p<0.01)$ marker:trait association for YI using markers sourced from YI-D2. However, the results were generally population specific, i.e. a unique locus / allele / phase combination was associated with increased YI and SY performance in four of the five populations (Table 1). Allele frequencies were also widely variable among populations (Table 1).

There were significant technical problems with the SSRs associated with the ID locus, which will be addressed with the development of new SSR markers and geneassociated markers in that region of linkage group C2.

Comparative mapping between white clover and Medicago truncatula is being used to identify candidate genes underlying and controlling these two QTLs, for use in developing next generation marker assays. Initial alignments with Medicago truncatula have identified a candidate for the ID-C2 locus, which is currently undergoing conversion into a DNA marker suitable for screening in white clover populations. MAS Outlook in forage species

QTL underlying major stable effects in white clover and ryegrass have been discovered in multiple independent research programmes, providing clear opportunities for development of forage MAS breeding. Initial investigation of forage MAS will require assessment of the breeding value of parents selected using MAS-informed vs. conventional methods, a thorough economic analyses, and development of MAS strategies which benefit from the unique nature of population-based breeding in obligate outcrossing forage species.

Breeders and DNA-marker specialists need to focus on developing appropriate means to implement practical MAS programmes in forage improvement. While MAS is reliant on a steady supply of QTL across the range of forage breeding traits (Abberton and Marshall 2005, Humphreys et al. 2006), the QTL discovery process is now routine. The major hurdle to implementation of MAS in forages is the design of cost-effective approaches compatible with the heterozygosity and heterogeneity of allogamous species, while also tackling the range of challenges generic to MAS breeding, from sample logistics to epistasis and pleiotropy.

A spectrum of MAS approaches have evolved in a variety of plant breeding systems and target traits, ranging from very low input to very high input approaches. A low-input approach using marker-assisted polycross breeding to monitor heterozygosity at anonymous marker loci in ryegrass polycrosses has shown promise (Kolliker et al. 2005). At the opposite end of the input and development cost spectrum are functional markers, that is allele specific DNA assays targeting genes encoding a desired phenotypic effect, potentially enabling direct selection of superior alleles across a range of germplasm (Sorrells and Wilson 1997). A range of intermediate approaches, such as 
marker assisted polycross breeding incorporating QTL associated markers, may also be suited to optimise the value of MAS in forages.

The preferred MAS approach will be identified on a trait by trait basis. Primary selection criteria will include trait heritability and complexity of genetic control, known effective alleles, and the value of the target trait to society.

Given proper resources, forage breeding via MAS, coupling the strengths of conventional breeding with the opportunity provided by MAS, has a bright future in the development of forage varieties with superior performance at the seed field, sward, and animal product level, contributing to a sustainable pastoral agriculture in Australasia.

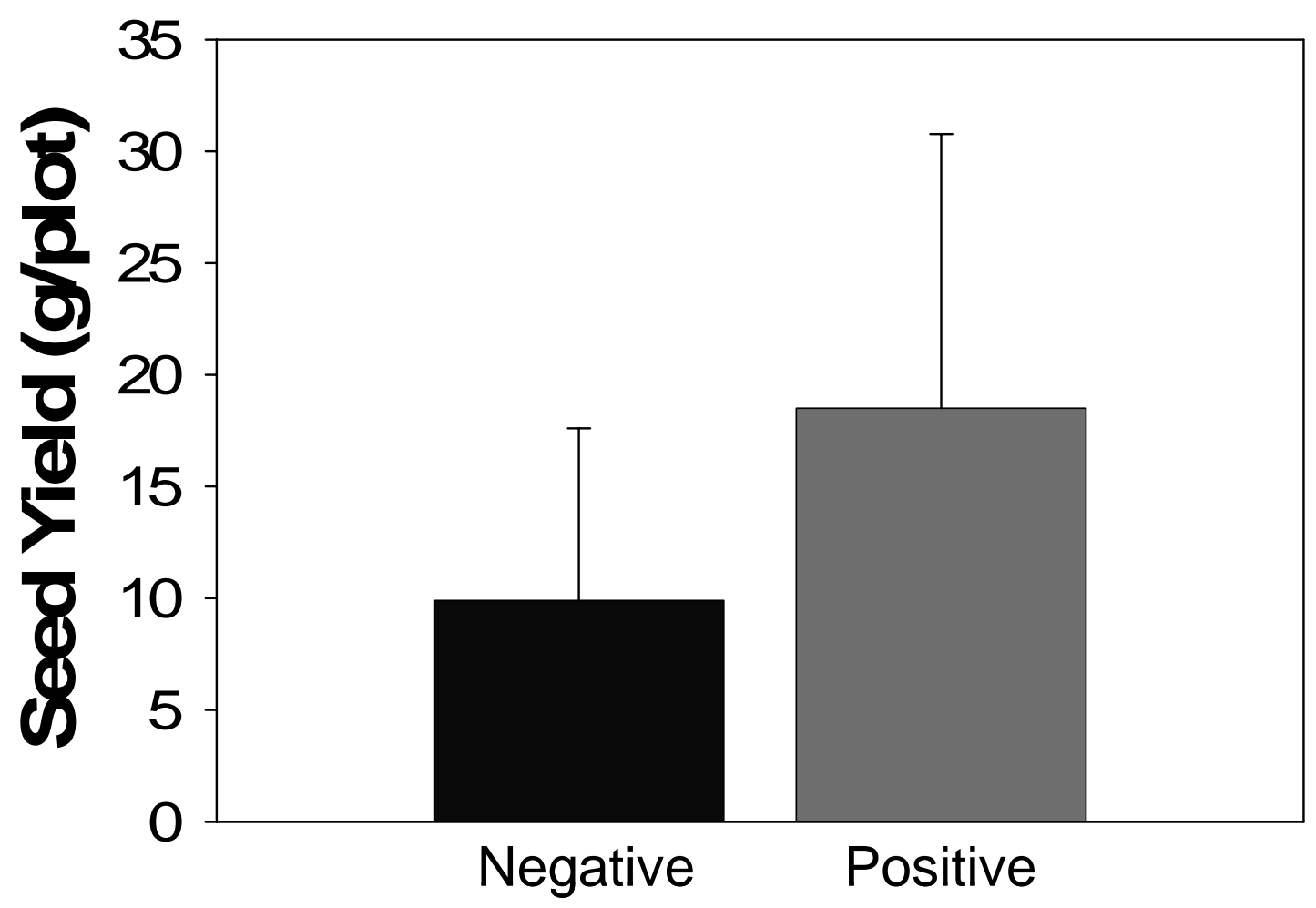

DNA Test Result

Figure 1. Trait-associated markers in white clover can identify individuals with significantly $(\mathrm{p}<0.001)$ increased trait performance. Plant performance was measured in the field during the 2003/04 growing season on a research farm in Lincoln, New Zealand. White clover SSRs ats113 and prs783 were used in tandem to test individual plants of a commercial white clover population undergoing parental selection trials for seed production. A 90\% increase in seed yield is indicated between the plants with the superior performance-associated allele for both marker tests, relative to the plants with the inferior performance-associated allele for both marker tests. The errors bars are indicative of the highly variable nature of white clover breeding populations. 
Table 1. Trait-associated markers are associated with differential performance of white clover on a population specific basis. Seven breeding populations were tested in the 2004/05 growing season using DNA markers at the YI-D2 QTL region. Five of the seven populations showed significant $(\mathrm{p}<0.01)$ associations between an SSR linked with QTL and differential trait performance among plants in the population. Data in this table indicate only the SSR allele associated with the greatest change in plant performance. Plants were screened in the field at Lincoln, New Zealand for seed yield potential, and in the laboratory with markers associated with YI-D2.

\begin{tabular}{ccccccccc}
\hline & & & \multicolumn{3}{c}{ DNA Test Result } & & \multicolumn{2}{c}{ Marker Allele Frequency } \\
Pop & SSR & Allele & $\begin{array}{c}\text { Positive } \\
\text { (SY \% change) }\end{array}$ & $\begin{array}{c}\text { Negative } \\
\text { (SY \% change) }\end{array}$ & p value & & Positive (\%) & Negative (\%) \\
\hline 1 & A & e & 14.2 & -54.7 & $<0.0001$ & & 18.4 & 81.6 \\
2 & B & g & 2.7 & -33.8 & 0.0074 & & 4.5 & 93.3 \\
3 & A & e & 26.2 & -5.7 & 0.0004 & & 76.8 & 20.3 \\
4 & A & e & 2.4 & -29.6 & 0.0065 & & 8.0 & 86.7 \\
5 & B & f & 5.2 & -25.1 & 0.0013 & & 15.2 & 82.6 \\
6 & C & i & 4.1 & -35.8 & $0.0122(\mathrm{~ns})$ & 6.9 & 85.6 \\
7 & A & g & 3.4 & -14.0 & $0.1590(\mathrm{~ns})$ & 30.5 & 66.9 \\
\hline
\end{tabular}

\section{References}

Abberton M, Marshall AH (2005) Progress in breeding perennial clovers for temperate agriculture. Journal of Agricultural Science 143, 117-135.

Barrett B, Griffiths A, Schreiber M, Ellison N, Mercer C, Bouton JH, Ong B, Forster J, Sawbridge T, Spangenburg G, Bryan GJ, Woodfield DR (2004) A microsatellite map of white clover. Theoretical and Applied Genetics 109, 596-608.

Barrett BA, Baird IJ, Woodfield DR (2005) A QTL analysis of white clover seed production. Crop Science 45, 1844-1850.

Faville M, Barrett B, Griffiths A, Schreiber M, Mercer C, Baird I, Ellison N, Bryan GJ, Woodfield DR, Forster J, Ong B, Sawbridge T, Spangenburg G, Easton HS (2003) Implementing molecular marker technology in forage improvement. Proceedings of the New Zealand Grassland Association 65, 229-238.

Faville M, Vecchies A, Schreiber M, Drayton M, Hughes L, Jones E, Guthridge K, Smith K, Sawbridge T, Spangenberg G, Bryan G, Forster J (2004) Functionally associated molecular genetic marker map construction in perennial ryegrass (Lolium perenne L.). Theoretical and Applied Genetics 110, 12-32.

Faville MJ, Crush J, Easton HS (2006) At the root of it all: a QTL analysis of root distribution in perennial ryegrass. In 'Breeding for Success: diversity in action. Proceedings of the $13^{\text {th }}$ Australasian Plant Breeding Conference, Christchurch, New Zealand'. (Ed. CF mercer) pp 303-311). www.apbc.org.nz

Francia E, Tacconi G, Crosatti C, Barabaschi D, Bulgarelli D, Dall'Aglio E, Vale G (2005) Marker assisted selection in crop plants. Plant Cell, Tissue and Organ Culture 82, 317-342.

Humphreys MW, Yadav RS, Cairns AJ, Turner LB, Humphreys J, Skot L (2006) A changing climate for grassland research. New Phytologist 169, 9-26. 
Jones E, Hughes L, Drayton M, Abberton M, Michaelson-Yeates T, Bowen C, Forster J (2003) An SSR and AFLP molecular marker-based genetic map of white clover (Trifolium repens L.). Plant Science 165, 531-539.

Kolliker R, Boller B, Widmer F (2005) Marker assisted polycross breeding to increase diversity and yield in perennial ryegrass (Lolium perenne L.). Euphytica 146, 55-65.

McCallum J, Kenel F, Pither-Joyce M, Abraham D, Barrett B (2006) Evaluation and Optimisation of Whatman FTA ${ }^{\circledR}$ Cards for DNA Sampling in Vegetable and Forage Genetics. In 'Breeding for Success: diversity in action. Proceedings of the $13^{\text {th }}$ Australasian Plant Breeding Conference, Christchurch, New Zealand’. (Ed. CF mercer) pp 640-644). www.apbc.org.nz

Sartie AM, Easton HS, Matthew C, Faville MJ (2006) A quantitative trait locus analysis of seed production traits in perennial ryegrass (Lolium perenne L.). In 'Breeding for Success: diversity in action. Proceedings of the $13^{\text {th }}$ Australasian Plant Breeding Conference, Christchurch, New Zealand'. (Ed. CF mercer) pp 377-382). www.apbc.org.nz

Sorrells ME, Wilson WA (1997) Direct classification and selection of superior alleles for crop improvement. Crop Science 37, 691-697.

Warnke SE, Barker RE, Jung G, Sim SC, Main MAR, Saha MC, Brilman LA, Dupal MP, Forster JW (2004) Genetic linkage mapping of an annual x perennial ryegrass population. Theoretical and Applied Genetics 109, 294-304.

Woodfield DR, Baird I, Clifford P (2004) Genetic Improvement of White Clover Seed Production. Proceedings of the New Zealand Grassland Association 66, 111-117.

Woodfield DR, Caradus JR (1994) Genetic improvement in White Clover representing six decades of plant breeding. Crop Science 34, 1205-1213.

Woodfield DR, Easton HS (2004) Advances in pasture plant breeding for animal productivity and health. New Zealand Veterinary Journal 52, 300-310. 